\title{
Satellite Altimetry: Observing Ocean Variability From Space
}

\author{
By Lee-Leung Fu, Dudley B. Chelton and Victor Zlotnicki
}

$\mathrm{D}$ currents with current meter arrays is difficult and costly on basin scales. Since large-scale currents are very nearly in geostrophic balance, their velocity can be calculated from the pressure gradient on an equigeopotential surface. The surface geostrophic current therefore can be calculated from the deviation of sea level from the equigeopotential at the ocean surface (the marine geoid). Measuring sea level from space by satellite altimetry thus offers a unique opportunity for determining the global surface geostrophic ocean circulation and its variability. Coupled with knowledge of the geoid and the ocean density field, satellite altimetry provides the only feasible approach for determining absolute geostrophic currents in the global ocean. Repeated altimetric observations of sea level at the same locations can resolve the variability of surface geostrophic currents, without the requirement for an accurate geoid model. In this paper, we briefly introduce the technique of satellite altimetry, highlight progress made in the past, assess the challenges that lie ahead, and discuss future plans.

\section{The Technique}

A satellite altimeter is a radar that precisely measures the range from the radar antenna to the ocean surface. A schematic summary of altimeter measurements and the corrections that must be applied to obtain dynamic sea surface elevation is shown in Fig. 1 (p.6). The altimeter transmits a short pulse of microwave radiation with known power toward the sea surface at satellite nadir (the point directly beneath the satellite). This pulse interacts with the sea surface, and part of the incident radiation reflects back to the satellite, giving the range from the 2-way travel time of the pulse. Near-surface wind speed and significant wave height also can be determined from the power and shape of the returned signal.

If the orbit height $H$ of the satellite relative to a reference ellipsoid is known from precision orbit

Lee-Leung Fu, Jet Propulsion Lahoratory, California Institute of Techology, Pusudena. CA 91/09; Dudley B. Chelton, College of Oceanngraphy. Oregon State University: Corrallis, $O R$ 97331: Victor Zlotnicki, Jet Propulsion Laboratory; Califormia Institute of Technolegy. Pasadena. CA 91109. determination techniques, the height of the sea surface relative to the same ellipsoid (the sea level) can be obtained by subtracting the altimeter range measurement $h$ from $H$ (Fig. 1). The dynamic sea surface elevation $h_{d}$ is then the difference between the sea level and the geoid height $h_{1}$. The magnitude of dynamic sea surface elevation ranges from $10 \mathrm{~cm}$ (gyre-scale currents) to over $1 \mathrm{~m}$ (western boundary currents and eddies), with variance spread over a wide range of wavenumbers and frequencies. The required measurement accuracy is thus dependent on the phenomenon of interest. Generally, an overall accuracy of better than $10 \mathrm{~cm}$ is required for observations of the dynamic sea surface elevation to be useful. Present knowledge of the global geoid is accurate to this level only at scales longer than about $5,000 \mathrm{~km}$. At shorter scales, present applications of altimetry are therefore limited to the study of temporal variability of ocean currents obtained from repeated altimeter measurements at the same locations, thus allowing removal of the time-invariant geoid. The accuracy of the sea level measurements then becomes the primary issue. Uncertainty in the altimetric measurement of sea level results from errors in the satellite range measurement $h$ and the orbit height $H$.

Errors in $h$ can be ascribed to three sources as indicated in Fig. I: instrumental errors, atmospheric refraction, and the interaction between the radar pulse and the air-sea interface. A thorough discussion of the elements of instrumental error is given by Chelton (1988). Briefly, instrumental errors consist of a random part and a systematic (long-wavelength) part. The random component is often referred to as the instrument precision. Since the earliest spaceborne altimeter flown on Skylab in 1973, the instrument precision for $1-\mathrm{sec}$ averaged data has improved from about $60 \mathrm{~cm}$, which barely resolved the sea surface slope across the Gulf Stream. to better than $4 \mathrm{~cm}$, which is sufficient to detect even small amplitude eddies in the ocean (Table 1, p. 10). Unlike random errors, the systematic component of instrumental error cannot be reduced by along-track averaging of the data. These systematic instrumental errors are still poorly understood and remain a challenge to altimeter engineers. 

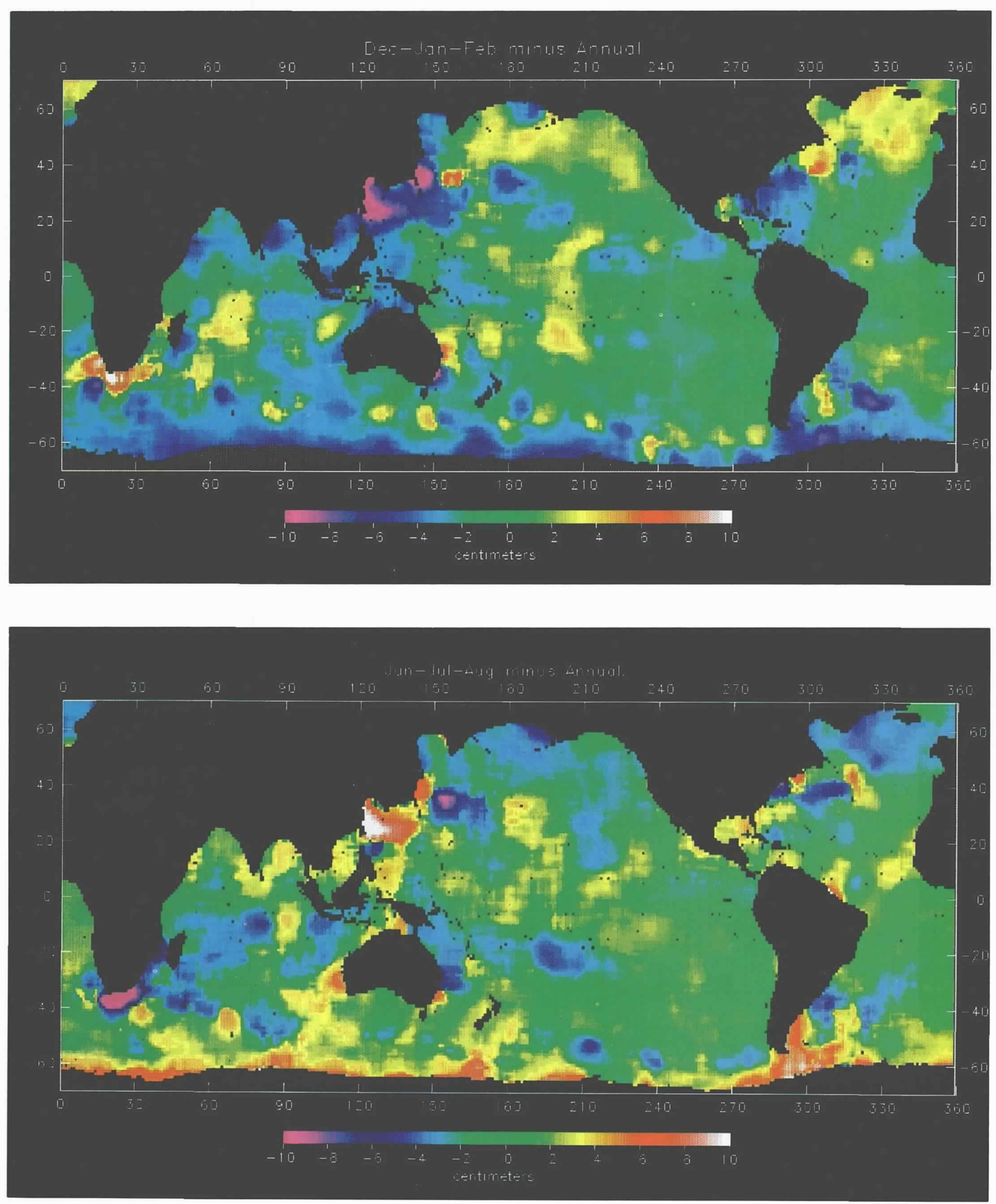

Figure 3. Upper Panel: Difference between mesoscale sea level variability during the northern hemisphere winter (December, January, February) and the annual average shown on the back cover. Differences are displayed in terms of the square root of the $1^{\circ}$ gridded variance differences, smoothed by a $9^{\circ}$ square median filter. Positive (negative) values correspond to anomalously high (low) wintertime eddy energy. Lower Panel: Same as the upper panel, except for the southern hemisphere winter (June, July, August). Data for both panels are from the first year of the Geosat exact repeat mission (December 1986-November 1987). 


\section{An improvement}

from $10 \mathrm{~m}$ for the

Skylab mission to

the $50 \mathrm{~cm}$ recently

achieved for Seasat

by Marsh et al. (1988)

is another major

achievement.
Uncertainty in $h$ introduced by atmospheric refraction result from decreases in the speed of light mainly due to dry gases (primarily oxygen), water vapor, and ionospheric free electrons along the propagation path of the radar pulse. The range error due to refraction by dry gases is large (approximately $230 \mathrm{~cm}$ ), but can be accurately corrected with knowledge of sea level atmospheric pressure obtained from meteorological models. The atmospheric water vapor content. however, cannot be predicted by meteorological models with sufficient accuracy for correcting the water vapor induced range error, which has a magnitude of $5-40 \mathrm{~cm}$. Accurate concurrent measurement of atmospheric water vapor from a passive microwave radiometer is required for this correction (Tapley et al.. 1982b). Similarly, present ionospheric models are not sufficiently accurate for correcting the ionospheric range error, which has a magnitude of $0.2-20 \mathrm{~cm}$. Direct measurement of the total electron content in the ionosphere is required. Since the ionospheric range error varies with frequency of the transmitted signal, radar altimeter measurements at two frequencies can be used to estimate the ionospheric range correction (Topex Science Working Group. 1981; Chelton, 1988).

Additional errors in $h$ result from the complex interaction of the altimeter pulse with the sea surface. The signal received by an altimeter is the radiation reflected by those specular scatterers within the pulse footprint. The range measurement is therefore related to the distribution of the specular scatterers, rather than true mean sea level. The difference between mean sea level and the mean scattering surface is referred to as the electromagnetic (EM) bias. The power backscattered from wave troughs is greater than that from wave crests, which biases the range measurements below true mean sea level. Since EM bias tends to increase with wave height, it is generally expressed as a percentage of significant wave height ( $\mathrm{SWH}$ ), defined to be 4 times the standard deviation of wave height. Estimates of EM bias derived empirically from in-orbit measurements range from $1-4 \%$ of SWH, but with uncertainty as large as the correction (Born et al., 1982).

Because of the pulse compression technique used in the present altimeter design (Chelton, 1988), the range measurement is referenced to the median height, rather than the mean height of the specular scatterers. If the sea state probability density function (pdf) is Gaussian, the two heights are the same. However, the sea state pdf is usually non-Gaussian and the difference between the two heights, called the skewness bias, is proportional to the skewness of the sea state pdf. The magnitude of the skewness bias can be 1$4 \mathrm{~cm}$. depending on the skewness and SWH. The skewness bias can be corrected with ground-based processing by analyzing the details of the received altimeter pulse shape (the waveform). However, this correction has not been established as a standard step in altimeter data processing.

The component of the sea level measurement

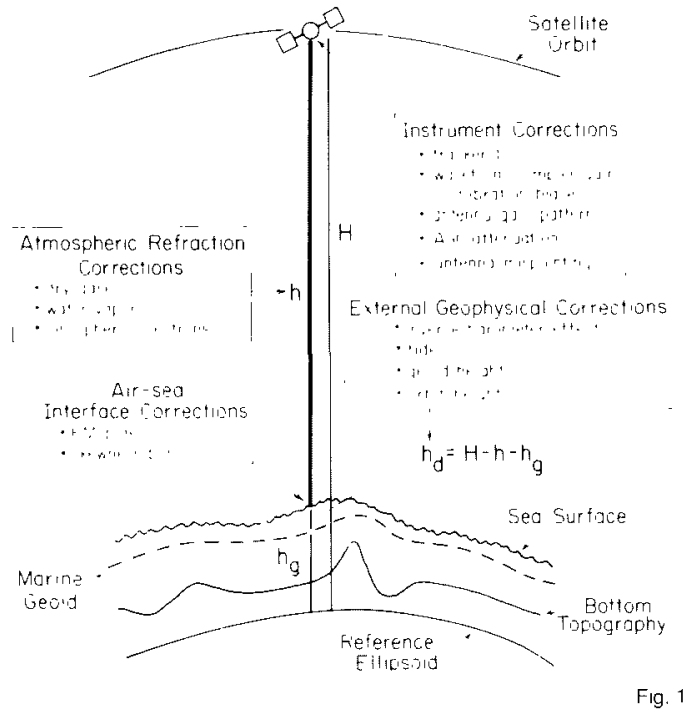

Figure 1. A schematio sammury of altmeter measurements and the comections that mast he applied ob obtain the dramic sea surface elevation h. The altimeter range' measurement is hand $H$ and he are the shit heisht and gerold height. respectively, relatre to a reference ellipsend approvimanom to the carthis surtuce.

Figure 2. Sea level at Majure in the westem tropical Pacific (7.1' N. 171.4 E). Line withont symbols is a low'pass filtered

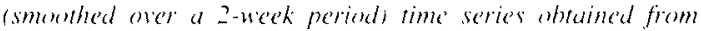
Geosed altimeter data. Line with plas symbels is ohaincel from a cubic-splene fit of monthly mean values from the Majuro tide gage' Mfter Cheney and Miller. Mosi's.

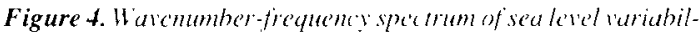
ity estimated from $G$ essat alimeter data in the Agulhas retroflectiom region south of Africa. The spertrum is presented an an

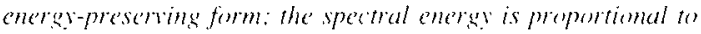

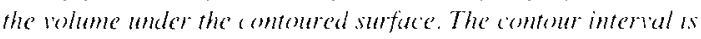
$10)^{2} m^{2}$ and areas one 50$)^{\prime} m^{2}$ are stippled.

error resulting from uncertainty in the orbit height $H$ is due to the lack of continuous direct observations of the satellite position. The orbit height is usually determined by statistical estimation based on assimilation of sparse tracking measurements into a dynamical orbit model. The main elements of the model include the earth's gravity field, solar and terrestrial radiation pressures. and atmospheric drag. The evolution of orbit accuracy for altimetric satellites is summarized in Table 1. An improvement from $10 \mathrm{~m}$ for the Skylab mission to the $50 \mathrm{~cm}$ recently achieved for Seasat by Marsh et al. (1988) is another major achievement over the 15 year history of satellite altimetry. This increase in accuracy results mainly from improvements in knowledge of the earth's gravity field, the dominant source of error in determining orbit accuracy.

Given the best altimetric estimate of sea level, it is still necessary to remove the effects of tides and atmospheric pressure loading (the inverse barometer effect) to enable studies of geostrophic currents from altimetric data. The solid earth tides and the ocean tides cause sea level displacements of about $20 \mathrm{~cm}$ 

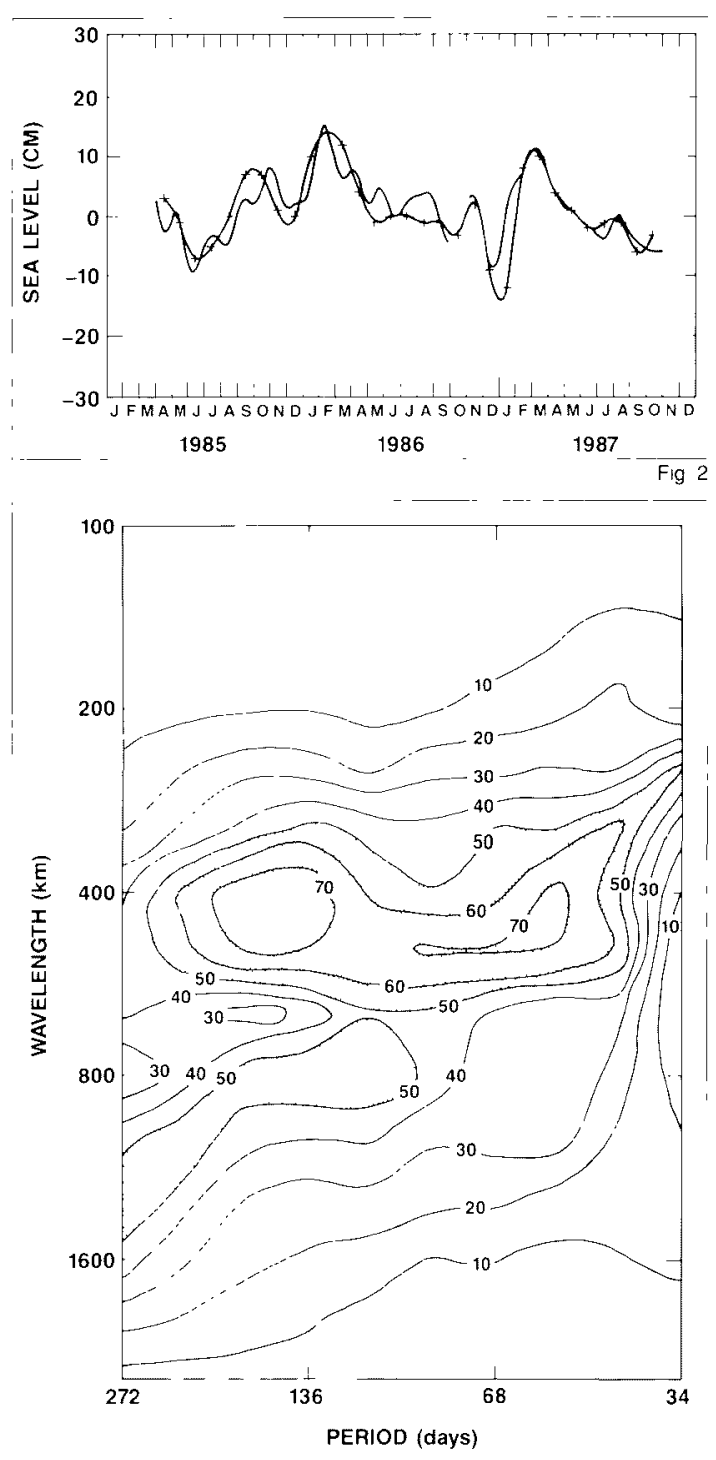

and $1 \mathrm{~m}$, respectively (Tapley et al., 1982a). The effects of solid earth tides, including the loading of the ocean, can be modeled with an accuracy of better than $1 \mathrm{~cm}$. The uncertainty of present ocean tide models is at least a factor of ten times larger. However. estimates of ocean tides with centimetric accuracies can be obtained from an altimeter flown in a carefully chosen orbit that samples the ocean in such a way that the aliased tidal frequencies are well separated from each other and from the zero and the annual frequencies (Parke et al.. 1987).

The sea level response to atmospheric pressure results from the downward force on the sea surface due to the mass of the overlying atmosphere. At certain frequencies and wavenumbers, the ocean responds to sea level atmospheric pressure in an "inverse barometer" sense: the sea level moves up and down by about $1 \mathrm{~cm}$ per millibar change in atmospheric pressure such that there is no net pressure change at depth associated with atmospheric pressure changes. These isostatic changes in sea level are unrelated to surface geostrophic currents and therefore must be removed to obtain the dynamic sea surface elevation. The detailed wavenumber-frequency characteristics of the transfer function between sea level and atmospheric pressure loading are poorly known, and they are likely to vary geographically. The accuracy of the inverse barometer correction is thus limited by uncertainties in both the actual atmospheric pressure and in the transfer function between sea level and atmospheric pressure loading.

It is apparent from the above summary that the basic principle of satellite altimetry is deceptively straightforward. The procedure for attaining highly accurate measurements of sea level is quite complex. requiring a multidisciplinary approach. None of the previous nor existing altimeter missions have implemented the full suite of corrections discussed above. Many of the corrections that have been applied are based on relatively crude models and inaccurate observations. Notwithstanding these deficiencies, tremendous progress has been made in application of altimeter data to study the circulation of the ocean. Progress

Applications of satellite altimetry have been reviewed by Fu (1983) and Douglas et al. (1987). The key factor that has allowed progress in the use of altimetry to study ocean circulation, despite sizable errors in the measurements, is the recognition by oceanographers that there is a separation of scales between signals and errors. For example, the orbit error, which is the dominant error in altimetric sea level measurements, has a predominant length scale of one orbit revolution (about $40,000 \mathrm{~km}$ ). For the study of features such as mesoscale eddies, which have much shorter along-track scales, the orbit error can be treated as a secular trend and removed by least squares procedures without affecting the signals of interest. Moreover, many of the altimetry errors (e.g., tides, water vapor range delays, inverse barometer effects, EM bias, etc.) have length scales longer than the oceanic mesoscale and can therefore also be separated from signals associated with mesoscale variability. As a result, mesoscale eddies have been the phenomenon in the ocean most studied from satellite altimeter data.

The instrument precision of the Skylab altimeter was inadequate to detect unambiguously even the sea level variability associated with the Gulf Stream. The first oceanographically useful altimeter measurements were made by the Geos-3 Mission (April 1975-December 1978), which gave continuous coverage only in the western North Atlantic. In spite of crude precision and accuracy, the Geos- 3 data have been used to produce a map of Gulf Stream mesoscale variability that compares well with historical ship observations (Douglas et al., 1983). Fu et al. (1987) demonstrated that a seasonal signal in the surface current of the Gulf Stream could be detected from the Geos-3 data.

The Seasat altimeter (July-October 1978) was the first designed for oceanographic applications. An on-board microwave radiometer was used to estimate the water vapor range correction. Precision
The

procedure

for attaining

highly accurate

measurements of

sea level is quite

complex, requiring a

multidisciplinary

approach. 


\section{Sea surface Slope Variability From GeOsat, 11/86-9/87}
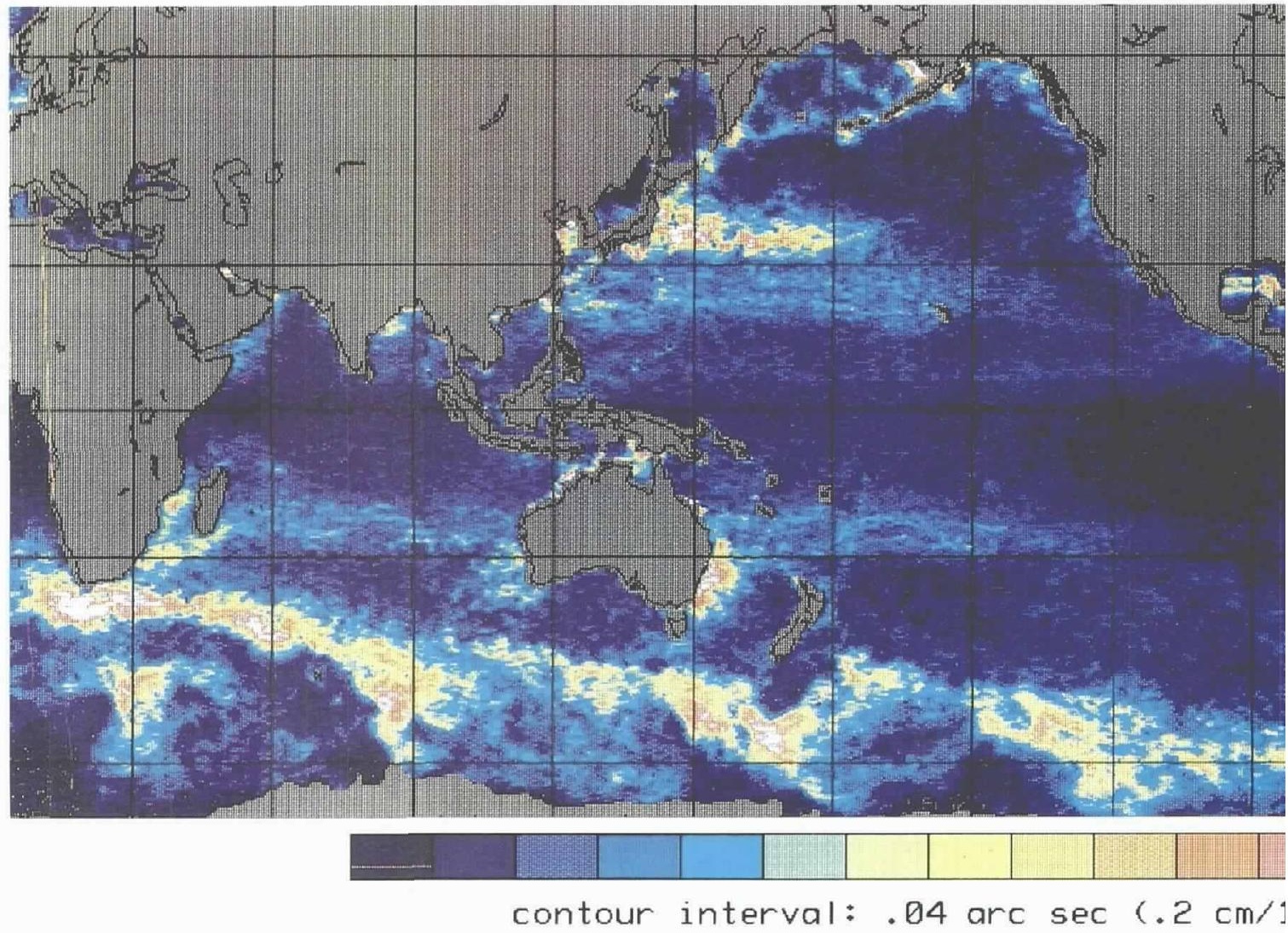

By William F. Haxby

ABOve is shown a map of sea level slope variability, based on an analysis of colinear Geosat altimeter profiles of ocean surface topography. The map was produced through the analysis of a 325 day sequence of Geosat exact repeat mission (ERM) altimeter data (19 repeat cycles). Altimeter profiles were first adjusted to remove long wavelength orbit errors, and data points ( 1 second along-track averages) with estimated errors greater than $10 \mathrm{~cm}$ were eliminated from the data set. The root-mean-square slope variability, $\sigma$, was determined from differences in sea surface slope between individual profiles and the 325 day mean profile, through a least squares analysis of overlapping $50 \mathrm{~km}$ track segments. Tracks that were sampled by less than 10
Geosat passes were excluded from the analysis. Along-track estimates of $\sigma$ were used to compute the mean $\sigma$ for $0.4^{\circ}$ geographic grid cells. Unsampled grid cells were assigned values of $\sigma_{s}$ based on bilinear interpolation. Tidal fluctuations predicted by the Schwiderski tide model were subtracted from the data prior to analysis, but there is high variability in some areas that can be attributed to tides: the northern margins of Brazil and Australia, for example. The rms slope variability shown has maximum values of about $30 \mathrm{~cm}$ per $100 \mathrm{~km}$ in the regions of brightest colors (pale blues to whites), as shown on the accompanying color scale bar. Map and caption contributed by William F. Haxby, LamontDoherty Geological Observatory, Palisades, NY 10964. orbit determination has recently resulted in a Seasat orbit accuracy of better than $50 \mathrm{~cm}$ (Marsh et al., 1988). Seasat altimeter sea level measurements have been shown to agree with dynamic heights computed from aircraft expendable bathythermographs to an accuracy of $10 \mathrm{~cm}$ at scales up to order $1000 \mathrm{~km}$ (Bernstein et al., 1982). With the Seasat data, oceanographers began to develop confidence in the quality and utility of altimeter measurements.

An important aspect of the Seasat mission is the availability of a nearly continuous global data set for the 3.5-month mission, providing the first global perspective of sea surface topography and its variability. Using only data from the last month, when Seasat was flown in a 3-day repeat orbit, Cheney et al. (1983) produced a map showing the global distribution of mesoscale sea level variability. Mazzega (1985) and Woodworth and Cartwright (1986) produced altimetrically-determined global charts of the M2 tide. Using a mean sea surface computed from the Seasat data, Tai and Wunsch (1984) derived the first global absolute dynamic topography, showing 


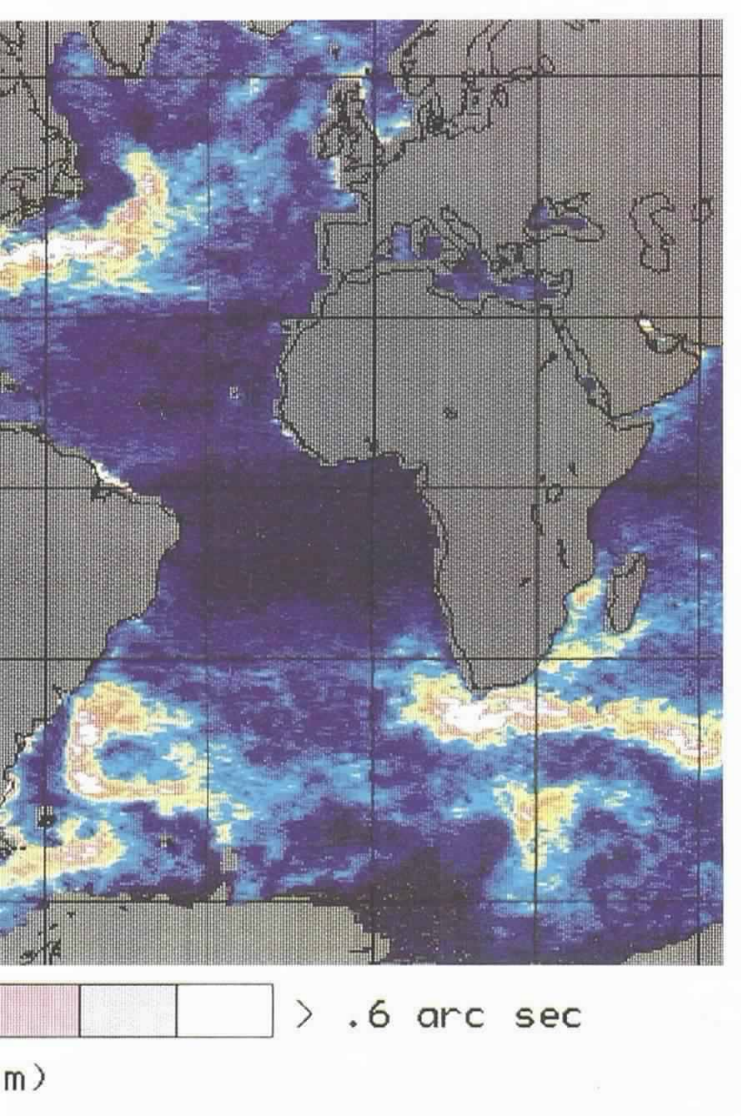

Editor's Note: Fluctuating surface geostrophic currents should be closely related to the sea surface slope variability. which Haxby's map above shows occurs in regions that closely match the regions of high variability of undifferenced Geosat sea level height data (cf. Fu, Chelton and Zlotnicki. this issue, p. 5). The similarity suggests that sea level height may be a good proxy for sea level slope in strong-current regions, which is sensible if slope changes across a current are mostly due to height changes confined to one flank of the current. Both the Haxby and the Fuet al. maps clearly identify western boundary currents, the Antarctic Circumpolar Current. the Aghulas Retroflection, and the Brazil-Falkland Confluence as areas of high variability. The same areas stand out in modeled fluctuations of thermocline temperature in the global ocean (cf. front cover and caption by Semtner, this issue).

many qualitatively plausible patterns of the longwavelength components of the mean circulation of the world ocean. Fu and Chelton (1985) used Seasat altimeter data to study the large-scale temporal variability of the Antarctic Circumpolar Current for the period July-October 1978.

The most serious limitation of the Seasat mission is its short 3.5-month duration, which has made many scientific results largely qualitative. The Seasat data have been extremely useful, however, for developing techniques for analyzing other altimeter data sets.
The U.S. Navy Geosat Mission has been collecting global altimeter data since March 1985. This multiyear data set has generated a new wave of enthusiasm for satellite altimetry. The primary objective of Geosat is to map the mean sea surface topography with high spatial resolution for Navy applications. This objective was completed during the first 18 months of the mission. The sea level data from this part of the mission have been classified by the Navy, but beginning in early November 1986, Geosat was maneuvered into a 17-day repeat orbit for oceanographic applications. The data from this so-called exact repeat mission (ERM) are unclassified and have been processed and distributed to the public by the $\mathrm{Na}$ tional Oceanic and Atmospheric Administration. A limitation of the Geosat mission is that the data are somewhat compromised by uncertainty in the water vapor range correction. Unlike Seasat, there is no onboard microwave radiometer on Geosat. The water vapor range correction is therefore based on Navy model estimates of water vapor. These water vapor fields are at least a factor of two less accurate than microwave radiometer estimates (Tapley et al., 1982b) and do not resolve spatial scales of variability shorter than about $2000 \mathrm{~km}$.

Although the sea level data from the first 18 months of the Geosat mission are classified, the differences between altimetric sea level measurements at intersections of ascending and descending ground tracks are not. Using a method developed by Fu and Chelton (1985), Cheney and Miller (1988) have combined the 18 months of crossover difference data with the ERM data to construct a multi-year gridded array of sea level time series in the tropical Pacific. Shown in Fig. 2 (p.7) is the comparison of a 2.5 year low-pass filtered altimeter sea level time series with a concurrent monthly-averaged sea level record from a tide gauge at Majuro in the western tropical Pacific. The rms difference between these two low-pass filtered time series is only $3 \mathrm{~cm}$, a remarkable result considering the errors in orbit height, the large water vapor content, and the strong horizontal gradients of water vapor in the tropics. The reason for the success is the scale separation between signals and errors, as discussed previously. The sea level variability is caused by equatorially trapped motions which have a limited along-track extent, such that long-wavelength orbit height and water vapor errors can be safely removed without sacrificing the signal of interest. The Geosat sea level observations are presently being used to study the 1986-87 El Niño (Cheney and Miller, 1988).

The Geosat data are also being used to study global mesoscale variability. The ERM data are collected along closely repeating (within $1 \mathrm{~km}$ ) ground tracks, so the use of the data for studying the temporal variability of ocean currents is fairly straightforward. Displayed on the back cover is a global map showing the geographic distribution of the standard deviation of sea level measurements made along repeat tracks during the first year of the ERM. There are two
The reason for the success is the scale separation between signals and errors. 


\section{Over the}

past fifteen years,

the satellite altimeter

has matured from an

experimental sensor

into an important

instrument for

oceanographic

research significant improvements in this map over the map of Cheney et al. (1983), oblained from one month of Seasat data. First. the magnitude of the sea level variability estimated from the Geosat data is more representative of the total frequency spectrum of mesoscale variability because of the much longer duration of the Geosat data. Second, the Geosat map reveals more detail than the Seasat map because of the much closer ground track spacing (equatorial crossings separated by $164 \mathrm{~km}$ for Geosat $15.935 \mathrm{~km}$ for the repeat orbit period of the Seasat mission).

It is well-known that the wind stress over the ocean is stronger in winter than in summer, so the part of the mesoscale variability that is directly driven by wind would be expected to have a similar seasonal cycle. Shown in Fig. 3 (p. 5) are global maps of the difference in sea level variability between the annual mean (shown on the back cover) and winter and summer seasonal means. Significant seasonal variations are found in many regions, among which the northeastern Pacific, the southeastern Pacific, and the northeastern Atlantic are indeed regions where winds are a significant source of eddy energy. The mechanisms for the seasonal variability evident in other regions (e.g.. the Gulf Stream, the Kuroshio, and the Antarctic Circumpolar Current) are yet to be explored. It is also possible that part of the apparent seasonal differences result from other sources of variability unrelated to the winds, e.g. long-period instabilities. Also see the article by Gordon in this issue, the front cover model results by Semtne'r, and the sidebar by Haxby accompanying this article (p. $8-9)-E d$.)

The sampling scheme of the Geosat ERM offers an opportunity to map the synoptic field of mesoscale eddies for the study of their dynamics. To illustrate the sampling capability of Geosat, shown in Fig. 4 (p. 7) is a wavenumber-frequency spectrum of sea level variability estimated from ERM data from a region south of Africa where the eddy energy is among the strongest in the world. The bulk of the eddy energy is contained in a spectral domain with wavelengths longer than $200 \mathrm{~km}$. indicating that the Geosat $110 \mathrm{~km}$ track spacing (at $40^{\circ}$ latitude) is adequate for resolving the eddy spatial scales. At wavelengths from 300 to $600 \mathrm{~km}$, the frequency distribution of energy shows a rapid drop in energy at periods slightly longer than 34 days, the shortest period resolved by the data. In this wavenumber band, the Geosat 17-day repeat data are thus adequate for resolving the eddy time scales as well. Ocean modelers are beginning to incorporate synoptic Geosat observations into numerical ocean models to improve simulations and even predictions of ocean dynamic processes (Walstadt, personal communication).

Over the past fifteen years, the satellite altimeter has matured from an experimental sensor into an important instrument for oceanographic research. While measurement accuracy has undergone an improvement of more than an order of magnitude, it is still not

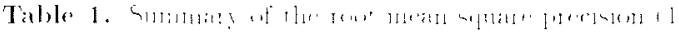

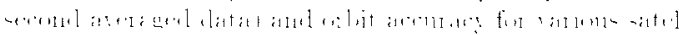
LIt1 alt $1111, \cdot 1,: 4$

\begin{tabular}{|c|c|c|}
\hline Sille ilite & 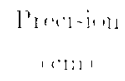 & 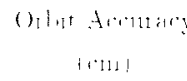 \\
\hline $4 l_{i} l_{i 1} 1,19, i_{1}$ & 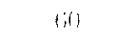 & 1.11110 \\
\hline 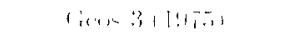 & 20 & $2(11191.17(1)$ \\
\hline Sentitl $19 \pi-1$ & $\therefore$ & $511 \quad 1001$ \\
\hline 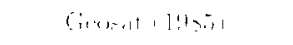 & $t$ & 501110 \\
\hline Elis I 1:4ma & ; & $.01) \quad 1110$ \\
\hline 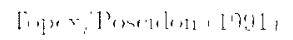 & 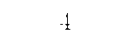 & $10 \because 20$ \\
\hline
\end{tabular}

Table 1

sufficient for the study of basin-scale variability and the time-mean circulation of the ocean. These are among the least known characteristics of the ocean. and yet they bear profound influence on the climate system of the earth. Satellite altimetry has the promise for making significant advancements in these areas. The challenge facing the oceanographic community is to push present capabilities one step further to realize this promise.

\section{Challenges}

To be useful for studying the basin-scale variability and the time mean circulation of the ocean. the altimetric sea level measurement must have an overall accuracy on the order of $10 \mathrm{~cm}$ or better. Given present and projected near-future capabilities in precision orbit determination, the overall accuracy will be dominated by orbit error of this same order. It is therefore essential that the accuracy of each of the other corrections applied to the altimeter range measurement he kept to a level much better than $10 \mathrm{~cm}$.

To evaluate the accuracies of the important altimeter geophysical algorithms, a workshop was held at the Oregon State University in Corvallis. Oregon, in August 1987 (Chelton, 1988). A major conclusion from this workshop was the identification of two areas where the physical basis for correction algorithms is not adequately understood. The first is the instrument and air-sea interface correction; the second is the inverse barometer correction. Most of the existing algorithms in the first category are based on empirical studies, so the resulting corrections are prone to bias errors related to sea state and altimeter antenna mispointing. The potential for ground-based analysis of altimeter waveform data to reduce instrumental and air-sea interface errors has been identified as a high priority item for investigation. The inverse barometer correction is actually a research problem for physical oceanographers. An improved understanding of the wavenumber-frequency response of the ocean to atmospheric pressure forcing is required.

Since the largest source of error in altimetric sea level measurements is uncertainty in orbit height. 
any significant improvement in the accuracy of altimeter estimates of sea level will require improvements in the knowledge of the earth's gravity field. A major accomplishment has recently been made by Marsh et al. (1988) in developing a much improved gravity model that is able to achieve an rms orbit accuracy of $25 \mathrm{~cm}$. This model is derived solely from satellite tracking data and is better than the best previous "satellite-only" gravity model by a factor of two. By incorporating Seasat altimeter data into the model development effort, an orbit accuracy of about $18 \mathrm{~cm}$ can be attained (Marsh et al., 1988). After "tuning" the model using the tracking data for a particular altimeter satellite, the orbit accuracy for that satellite can be even further improved.

As noted previously, an accurate geoid model is required for obtaining information about the timemean ocean circulation. The required accuracy of a few $\mathrm{cm}$ over a length scale of $100 \mathrm{~km}$ cannot be achieved by the Marsh ot al. (1988) gravity model based on existing satellite tracking data. The only feasible approach is to fly a gravity mission utilizing satellite-to-satellite tracking or gradiometry techniques (Topex Science Working Group, 1981 ). Temporal variations in the geoid can generally be ignored for the study of ocean circulation. The geoid therefore need not be measured concurrently with the altimetry measurements. The time-mean circulation can be derived retrospectively when a sufficiently accurate geoid eventually becomes available.

Besides the technical challenges of improving the overall measurement accuracy of altimeter observations, new techniques for utilizing the altimeter data must be developed. Major research efforts are underway to develop techniques for combining altimeter data, in situ observations. and numerical and statistical models to extract the most information possible from these different approaches for studying ocean circulation. The altimeter measures the surface geostrophic circulation globally. In contrast, in situ measurements from current meter moorings and hydrography measure the vertical structure of the ocean at specific locations. By combining these two observational data sets with models using data assimilation techniques, optimized 4-dimensional pictures of ocean circulation can be obtained. The challenges include development of techniques for capitalizing on the strengths of altimetric data. In particular, methods must be developed for utilizing the longwavelength altimetric sea level (for which the geoid is known accurately) or time-variable sea level from repeated altimetric measurements at the same locations.

\section{Future Missions}

There are two satellite altimeter systems scheduled to be launched in the early 1990 s. One consists of a pair of altimeters on the Topex/Poseidon dedicated altimetric satellite. The other is one of several instruments on the European Remote Sensing satellite ERS-1. The Topex/Poseidon Mission is jointly planned by the U.S. National Aeronautics and Space
Administration (NASA) and the French space agency Centre National d'Etudes Spatiales (CNES). This mission has been optimally designed for studying the world ocean circulation. The satellite will orbit at an altitude of $133.5 \mathrm{~km}$ with an inclination of $65.1^{\circ}$. The relatively high orbit was chosen to minimize both the atmospheric drag on the satellite and the influence of gravity errors on orbit accuracy. The orbit inclination was chosen to satisfy rather stringent requirements imposed by tidal aliasing and precision orbit determination. The primary Topex/Poseidon altimeter, designed and built by NASA, will make simultaneous measurements at two frequencies $(5.3 \mathrm{GHz}$ and 13.5 $\mathrm{GHz}$ ) so that the ionospheric range correction can be directly estimated from the combined measurements. The other Topex/Poseidon altimeter is an experimental solid-state altimeter designed and built by CNES for future low-power and low-cost altimetermissions. Other sensors include a three-frequency microwave radiometer for determination of atmospheric water vapor for the water vapor range correction, a Doppler radio tracking system for precision orbit tracking. and an experimental Global Positioning System (GPS) tracking system that has the potential of providing continuous orbit tracking with an accuracy of better than 10cm (Yunck ct al., 1985). The specification for overall measurement accuracy for a single pass is $14 \mathrm{~cm}$, which is dominated by an rms orbit error of $13 \mathrm{~cm}$. However, orbit improvement will be a continuing research effort that is expected to eventually reduce the orbit error to less than $10 \mathrm{~cm}$. The mission is scheduled to be launched by the French Ariane launch vehicle in December 1991.

The ERS-1 mission is planned by the European Space Agency and is scheduled to be launched in September 1990. Sensors will include a single-frequency altimeter and a microwave radiometer. The mission orbit is sun-synchronous with an altitude of $800 \mathrm{~km}$ and an inclination of $98^{\circ}$. The overall measurement accuracy of the ERS-1 altimeter is expected to be comparable to that of the Seasat altimeter. The Topex/Poseidon and ERS-1 altimeter data sets will be complementary, and to the extent that they overlap, the Topex/Poseidon orbit will help calibrate the ERS-1 orbit. The combined Topex/Poseidon and ERS-1 altimeter data sets will provide information about ocean variability with unprecedented accuracy and temporal and spatial resolution. With the in situ observations. numerical modeling, and data assimilation efforts anticipated as part of the World Ocean Circulation Experiment. the decade of the 1990 s promises major advancements in our understanding of the circulation of the world ocean.

Acknowledgements

The research described in this paper was carried out at the Jet Propulsion Laboratory, Californiat Institute of Technology, under contract with the National Acronautics and Space Administration (NASA), and at Oregon State University under Contract 958127 funded under the NASA Topex/Poseidon Announcement of Opportunity.

[ PLEASE TURN TO PAGE 58 ]
The combined Topex/

Poseidon and ERS-1

altimeter data sets will

provide information

about ocean variability

with unprecedented

accuracy and temporal

and spatial resolution. 
great success during the forty-five years since the school's founding. The resources available to students in the form of facilities, curriculum and faculty are extensive. The RSMAS library is accessible to students 24 hours a day, 365 days a year. Each student receives nearly unlimited time on the school's computing system, which includes links to a variety of academic and research networks. And, of course, individual divisions provide facilities equipped to satisfy research needs within their respective sub-disciplines. The small student-tofaculty ratio ( $\sim 2$ ) enables students to work closely with their advisors and to play an active role in research. These factors and more come together at the RSMAS to create an exceptional educational environment.

Despite the excellent provisions of the RSMAS, students have gone a step further and established two organizations to address student needs and concerns. These are the Marine Science Graduate Student Organization (MSGSO) and the Organization of Tropical Marine Science Students (OTMSS). Soon after the founding of the RSMAS, the MSGSO was established to insure student representation within the University. It has remained an active voice throughout the school's history. A representative of the MSGSO occupies a voting position on the school's Academic Committee and participates in the formulation of policy regarding students. The MSGSO also provides a number of services such as short-term, no-interest loans and new student orientation intended to help with the problems of "student life." As a means of promoting student-faculty exchange as well as student-student interaction, the MSGSO operates a commons complete with music and a full bar. Finally, the MSGSO has created a travel fund program to provide financial assistance to students presenting the results of their research at scientific meetings.

Monies allotted to this fund annually are matched by the Office of the Dean. Excluding the Dean 's matching funds, the MSGSO receives no monetary support from the University, and all of its annual budget is met through fund-raising activities. Chief among these is the Annual MSGSO Student Auction, an event in which businesses and individuals donate their services and merchandise. The donations are auctioned with earnings going to the MSGSO. Last year the event raised nearly $\$ 8,000$.

The Organization of Tropical Marine Science Students was established in 1986 to promote activities which contribute di- rectly to the education and training of marine science students.

The OTMSS sponsors a number of field trips to various environments in South Florida and the Caribbean, stressing the importance of an interdisciplinary approach in the marine sciences. Through these organized trips, students gain direct exposure to. and an increased appreciation of, the sub-disciplines of their fellow students. Field trip leaders are faculty members or students with specialties in the areas to be visited. Beginning this fall, the OTMSS will sponsor a series of work shops directed at improving students' presentation skills.

\section{The South ATLANTIC [CONTINUED FROM PAGE 17]}

Revealed by Inverted Echo sounders.I.Geophss Rer. 92. (C2). 1914-1922.

Gordon. A. L. 1986: Inter-Ocean Exchange of Thermocline Water. I Gerphys. Res.. 9/(C+): 5037.5046.

Gordon. A. L.. J. R. E. Lutjeharms and M. L. Gründlingh 1987: Stratification and Circulation at the Agulhas Retroflection. De'ep-Sed Res $341+1.56 .5-590$

Olson. D. B. and R. H. Evans, 1986: Rings of the Agulhas Current. De'p) Se'd Re's, 33, 27-42.

Ou. H.W. and W. de Ruyter, 1986: Separation of an

\section{Satellite Altimetry [CONTINUED FROMI PAGE I1]}

\section{References}

Bemstein. R.L.. G.H. Born and R.H. Whritner, 198 ? Seasat altimeter determination of ocean current varability. I Gesphys. Re's. 87. 3261-3268.

Born, G.H. M.A. Richards and G.W. Rosborough. 1982: An empirical determmation of the effect of sea-state bias on the SEASAT altimeter. $J$ Geopless. Re's. 87. 3221-3226.

Chelton, D.B. 1988: WOCE/NASA Altmeter Algorithm Workshop. U.S. WOCE Tech. Rep. No. 2. U.S. Planning Office for WOCE, College Station. TX.. 70 pp.

Cheney, R.E., J.G. Marsh and B.D. Beckley, 1983: Global menoscale varability from collinear tracks of Seasat altimeter data. J. Goophys Res, 88. $4.343+4.354$

Cheney. R.E., and L. Miller. 1988: Mapping the 1986-1987 El Viño with Geosat altimeter dati. Eos Trams. Amler. Gerophys. Union. 69, 754-755.

Douglas. B.C.. R.E. Cheney and R.W. Agreen. 1983: Eddy energy of the Northwest Allantic and Gulf of Mexico determmed from Geos-3 altimetry. I Gaphos Res, Rig. 4595-9603

Douglus. B.C.. D.C. MCAdoo and R.E. Cheney. 1987: Oceanographic and geophysical applications of atellite altimetry. Rov. G(ophlys. 25. $875-880$

Fu. L.-L.. 1983: Recent progress in the application of satellite altmetry to observing the mesoscale variability and general circulation of the oceans. Rer. Geophys. Space Phys. 21, 1657-1666.

Fu. L.-L...J. Vasquez and M.E. Parke. 1987: Seasonal variability of the Gulf Stream from satellite at-
The importance of effective communication is fully recognized among students at the RSMAS, and the planned workshops will combine expert instruction with practical experience. Individual workshops will cover written and verbal skills, and will be lead by selected faculty members noted for their presentation skills.

The above are just a few of the ways that graduate students at the University of Miami's Rosenstiel School of Marine and Atmospheric Science are enriching the educational experience for themselves and their fellow students. We encourage other students to share their successes.

inertial boundary current from an irregular coastline. J. Phy. Ocedmogr.. 10. 280-289

Rintoul. S.. 1988: Mass, heat and nutrient fluxes in the Atlantic Ocean determined by inverse methods. Ph.D. thesis, Massachusetts Institute of Technology/Woods Hole Oceanographic Institute Joint Program, 287 pp.

Roden. G., 1986: Thermohaline fronts and baroclinic flow in the Argentine Basin during the austral spring of $1984 . I$ Goophys. Re's., 91. 5075 5093.

Whitworth. T. and W. Nowlin, 1987: Water masses and currents of the Southern Ocean at the Greenwich meridian. I. Geophys Res..92,6462$6+76$.

timetry. I. Geophys. Res. 92, 749-754.

Fu. L.-L.. and D.B. Chelton, 1985: Observing largescale temporal variability of ocean currents by satellite altimetry: with application to the Antarctic Circumpolar Current. $J$. Geophys. Res., 9(). $4721-4739$.

Marsh, J.G.. (and 19 other authorst. 1988: A new gravitational model for the earth from satellite tracking data: GEM-T1. I. Gerphys Re's.. 93. $6169-6215$.

Mazzega. P. 1985: M2 model of the global ocean tide derived from SEASAT altimetry. Mar. Good., $y$ $335-36.3$.

Parke. M.E.. R.H. Stewart. D.I. Farless and D.E. Cartwright. 1987: On the choice of orbits for at altimetric satellite to study ocean circulation and tides. J. Geophys. Re's. 92, 11.693-11.707.

Tai. C.-K., and C. Wunsch, 1984: An estimate of global absolute dynamic topography. J. Phy Oceanogr.. 14.457-463.

Tapley. B.D., G.H. Born, and M.E. Parke. $1982 \mathrm{a}$ : The SEASAT altimeter data and its accuracy assessment. J. Geoplyss. Res.. 87. 3179-3188.

Tapley, B.D., J.B. Lundberg and G.H. Bom. 1982b: The SEASAT altimeter wet tropospheric range correction. I. Geuphes. Re's., 87. 3213-3220.

Topex Science Working Group. 1981: Satellite altimetric measurement of the ocean. Doc. 400 111. Jet Propul. Lab., Pasadena, Calif.

Woodworth. P.L., and D.E. Cartwright. 1986: Extraction of the M2 ocean tide from SEASAT altimeter data. Gerphis I Rut Asto. Sex. Bt. $227-255$.

Yunch. T.P. S.C. Wu and S.M. Lichten, 1985: A GPS measurement system for precise satellite tracking and geodesy. I. Astronaut. Sol... 33 $367-380$. 